\title{
Sacroiliac joint arthrodesis for chronic sacroiliac joint pain: an anterior approach and clinical outcomes with a minimum 5-year follow-up
}

\author{
Eiichi Murakami, MD, PhD, ${ }^{1}$ Daisuke Kurosawa, MD, ${ }^{1}$ and Toshimi Aizawa, MD, PhD² \\ 1'Department of Orthopaedic Surgery/Low Back Pain and Sacroiliac Joint Center, JCHO Sendai Hospital; and 'Department of \\ Orthopaedic Surgery, Tohoku University School of Medicine, Sendai, Japan
}

\begin{abstract}
OBJECTIVE The authors evaluated the outcomes of sacroiliac joint (SIJ) arthrodesis via an original anterior approach to the upper anterior surface of the SIJ in patients with a minimum of 5 years' follow-up.

METHODS The authors performed anterior SIJ arthrodesis in 45 patients between 2001 and 2015. Of these patients, 27 (11 men and 16 women; mean age at surgery 49 [24-86] years) were followed up for a minimum of 5 years (average 113 months, range 61-157 months). In the 14 patients in the earlier period of this study, the authors used an anterior approach to expose the SIJ by separating the iliac muscle from the iliac bone and performed internal fixation. In the 13 patients later in the study, the authors changed to a pararectal approach, which involved an incision along the lateral border of the rectus abdominal muscle. Then, extraperitoneally, the upper anterior surface of the SIJ was exposed between the psoas major muscle and the iliac muscle.
\end{abstract}

RESULTS Among the 27 patients, 21 had unilateral anterior arthrodesis alone, 4 required additional posterior arthrodesis, and 2 required pelvic ring arthrodesis because of later pain on the opposite side. In the 21 patients with a unilateral anterior arthrodesis, outcome according to the modified Macnab criteria was excellent in 7, good in 11, and fair in 3. Outcomes were excellent, good, fair, and poor in 1 patient each among the 4 with additional posterior fusion. Outcomes were good and poor for 1 patient each among those with pelvic ring arthrodesis. All 27 patients demonstrated bone union of the SIJ on CT. Lateral femoral cutaneous neuralgia developed in 7 of the 27 patients; 6 patients had undergone the initial anterior method and 1 the later method.

CONCLUSIONS Anterior SIJ arthrodesis was effective in most patients with severe SIJ pain resistant to conservative therapy. This approach has the advantage of direct curettage and bone graft into the wide area of the SIJ, which result in good bone union. In particular, the authors' current pararectal approach could decrease the potential risk of lateral cutaneous injury. https://thejns.org/doi/abs/10.3171/2018.1.SPINE17115

KEYWORDS sacroiliac joint; arthrodesis; anterior approach; clinical outcome; sacral; surgical technique

I N the early 20th century, Goldthwait and Osgood ${ }^{9}$ suggested that the sacroiliac joint (SIJ) could be the cause of low-back and leg pain. In 1934, however, Mixter and Barr $^{15}$ announced that sciatica originated from protrusion of the intervertebral disc; thus, the main cause of low-back and leg pain including sciatica has shifted to the lumbar intervertebral discs. As the SIJ was thought to be almost immovable, it was not suitable as a possible source of lowback pain. Recently, however, many reports have pointed out that SIJ pain is referred not only to the low back but also to the groin area, the leg, and even the foot. ${ }^{3,6,24}$ In addition, nociceptors have been confirmed in the posterior sacroiliac ligaments. ${ }^{23}$ Therefore, the SIJ is recognized as one of the sources of low-back pain.

For SIJ pain, conservative therapies such as rest, oral analgesics, fixation with a pelvic belt, physical therapy, or SIJ infiltration should mainly be applied. However, if the pain is not improved using these conservative therapies, SIJ arthrodesis may be the treatment of choice. To date, a number of posterior, ${ }^{2,13,27}$ lateral, ${ }^{8,26}$ or anterior approaches $^{1,20,21}$ have been attempted; however, sufficient results have not been obtained. In recent years, new methods for

ABBREVIATIONS RDQ = Roland-Morris Disability Questionnaire; ROM = range of motion; SIJ = sacroiliac joint; VAS = visual analog scale.

SUBMITTED March 21, 2017. ACCEPTED January 31, 2018.

INCLUDE WHEN CITING Published online June 22, 2018; DOI: 10.3171/2018.1.SPINE17115. 
SIJ fixation such as the Distraction-Interference-Arthrodesis with Neurovascular Anticipation (DIANA) method via the posterior approach ${ }^{5}$ and the triangular implant system via the lateral approach ${ }^{22}$ have been developed and performed in many patients throughout Europe and the United States, with good results. However, as the results were short-term, the long-term results remain uncertain.

Based on the thought that sufficient curettage and bone grafting in the joint would be difficult through the lateral or posterior approach, we have mainly performed SIJ arthrodesis via an anterior approach, with the advantage of treating the joint under direct vision. ${ }^{16}$ In the present study, we evaluate the postoperative outcomes of SIJ arthrodesis using our original anterior approach to the upper anterior surface of the SIJ in patients with at least 5 years of follow-up.

\section{Methods}

Our institutional review board approved this study, and informed consent was obtained from all patients before their participation in the study.

\section{Diagnosis of SIJ Pain}

Patients with low-back pain and/or leg symptoms were evaluated radiologically. Plain radiographs and CT were used for preoperative evaluation of joint changes and inflammatory diseases in all patients. Magnetic resonance imaging was performed in the patients with suspected lumbar spine diseases such as disc herniation and canal stenosis. Patients with inflammatory findings in the blood test or on radiological examination were excluded. Then, as in our previous study, ${ }^{17}$ we diagnosed SIJ pain when the patient showed all three of the following criteria: 1) pain over the SIJ; 2) positive findings on at least one of the three provocation tests-Gaenslen's test, ${ }^{7}$ Patrick's test, ${ }^{19}$ or SIJ shear test ${ }^{3}$ and 3 ) reproduction of pain when an injection needle is inserted into the SIJ and subsequent improvement $\geq 70 \%$ in the pain after a local anesthetics injection into the SIJ under fluoroscopic guidance, as in our previous studies..$^{10,17}$

\section{Patient Selection for Arthrodesis}

Indications for SIJ arthrodesis were as follows: 1) inadequate responsiveness to conservative treatments including stabilization by pelvic belt, manipulation, or SIJ injections for more than 6 months; and 2) marked restrictions in daily living. Initially, we performed the posterior arthrodesis using three screws and a bone graft in three patients. Preoperative pain was relieved shortly after the surgery; however, considerable pain remained in all three patients, and they could not return to work. We concluded that this approach was insufficient for treating patients with severe SIJ pain, and we changed to the anterior approach.

Between 2001 and 2015, we performed anterior SIJ arthrodesis in 45 patients with severe SIJ pain. Among those patients, 27 had a 5-year minimum follow-up and their outcomes could be evaluated, and these subjects were included in this study. The patients included 11 men and 16 women, and their mean age at surgery was 49 years (range 24-86 years). The follow-up period averaged 113 months

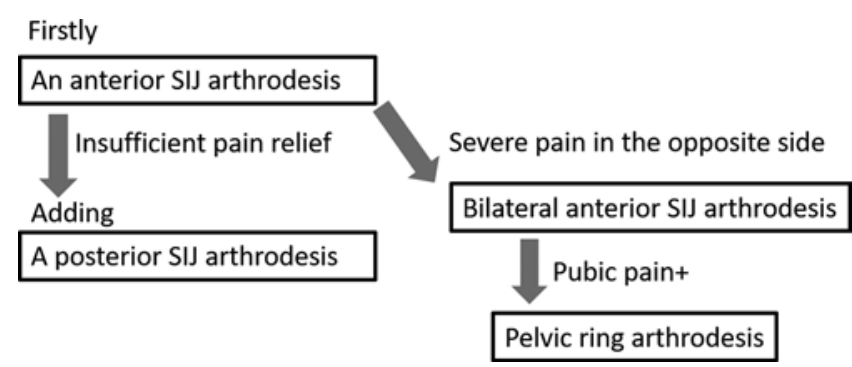

FIG. 1. Surgical algorithm.

(range 61-157 months). Three patients had previously undergone lumbar surgery before the SIJ arthrodesis.

\section{Surgical Algorithm}

First, we perform an anterior SIJ arthrodesis. If pain relief is not sufficient after this procedure, a posterior arthrodesis is added. If pain in the opposite side becomes severe after the anterior SIJ arthrodesis in the first side, bilateral anterior SIJ arthrodesis is performed (Fig. 1). We waited between 3 and 6 months postoperatively to decide whether posterior supplementation or contralateral arthrodesis was necessary.

\section{Surgical Procedures}

\section{Anterior SIJ Arthrodesis}

Early Anterior Approach. In the earlier period of this study, in the first 14 patients, we used an anterior approach to expose the SIJ by separating the iliac muscle from the iliac bone, similar to the approach used for open reduction and internal fixation in patients with pelvic fracture (Fig. 2). The SIJ was fixed using a plate and five screws (Fig. 3 ), one of which was at least inserted from the sacrum to the iliac bone to strengthen fixation of the joint. Firm retracting of the iliac muscle medially was needed for this purpose. However, there were the risks of increasing detachment of the iliac muscle and causing a lateral femoral cutaneous nerve injury, which can lead to pain and an inability to flex the hip.

Current Anterior Approach. Problems with the early approach were recognized. Therefore, we changed to a pararectal approach in the latter 13 patients (Fig. 4). An incision was made along the lateral border of the rectus abdominal muscle over the line of the SIJ. The upper anterior surface of the SIJ was then exposed using the extraperitoneal approach, between the psoas major muscle and the iliac muscle. It was not necessary to detach the iliac muscle from the iliac bone in this approach. The femoral nerve should be retracted laterally toward the iliac muscle because some branches of the femoral nerve are innervated to the iliac muscle. When the femoral nerve is retracted laterally in this approach, an upper anterior portion of the SIJ is safely exposed without bleeding problems or pelvic organ injuries.

\section{Posterior SIJ Arthrodesis}

After exposure of the lower half of the SIJ, the posterior joint space was curetted, and cancellous bones were 


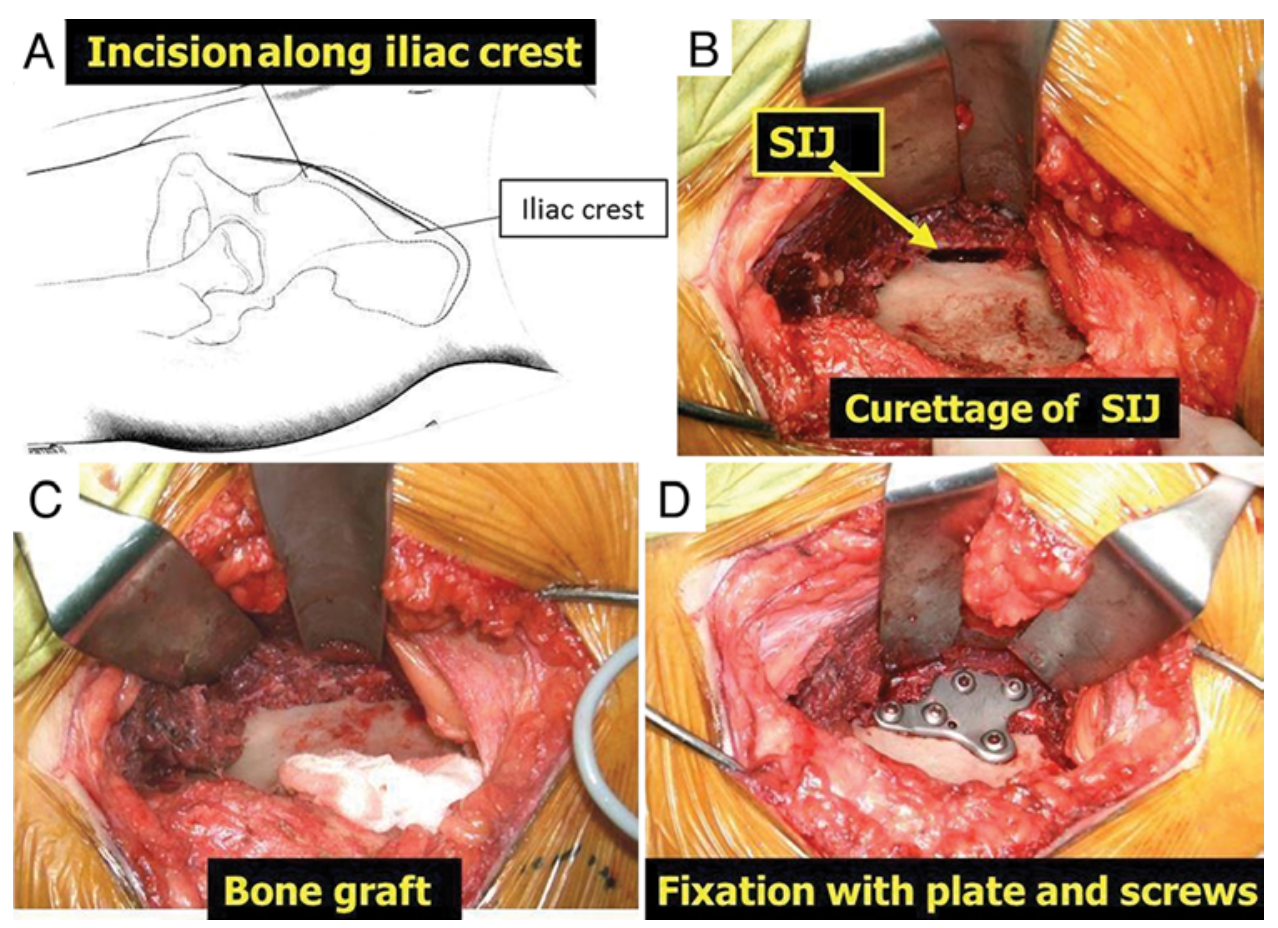

FIG. 2. Early anterior SIJ arthrodesis. A: The skin is incised along the iliac crest about $8-10 \mathrm{~cm}$, with the patient supine, keeping the hip slightly flexed. B: The iliac muscle is subperiosteally separated from the iliac bone to reach the anterior surface of the SIJ, and the joint space is curetted. C: The joint space is grafted with cancellous bone harvested from the iliac bone. D: The SIJ is fixed with a plate and five screws. Figure is available in color online only.

grafted from the posterior superior iliac spine. Then, two or three screws were inserted into the SIJ from the lateral side of the iliac bone under fluoroscopy.

\section{Pelvic Ring Arthrodesis}

We added fixation of the pubic symphysis using a plate and screws after bilateral anterior SIJ arthrodesis (Fig. 5).

\section{Postoperative Course}

The postoperative treatment for each procedure was basically as follows. After bed rest for 2-3 days, the patient was allowed to sit bedside. Walking with partial weight bearing was started at one-third at 2 weeks, half
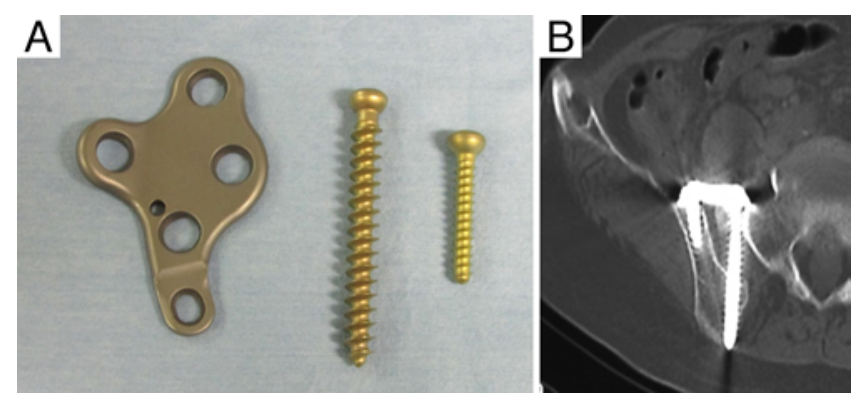

FIG. 3. Plate and screws for SIJ arthrodesis. A: Plate for SIJ arthrodesis (Next Medi International Co.), cancellous screw, and cortical screw. B: Computed tomography image after operation: one screw is inserted into the iliac bone from the sacrum. Figure is available in color online only. at 4 weeks, and two-thirds at $\geq 8$ weeks after surgery. Finally, walking with full weight bearing was permitted at 10-12 weeks postoperatively. In the patients with unilateral anterior SIJ arthrodesis alone, the hospital stay was 2-3 months long.

Bone union was examined by CT immediately after surgery; at 3 months, 6 months, and 1 year after surgery; and irregularly thereafter. In addition to assessing the complications that occurred during and after surgery, we evaluated clinical outcomes according to the modified Macnab criteria $^{12}$ and, among the patients with anterior arthrodesis alone, according to the pain relief scale ${ }^{11}$ (change in pain postoperatively compared with preoperatively, from a preoperative score of 10), visual analog scale (VAS) for pain, Roland-Morris disability questionnaire (RDQ), time sitting on a chair, walking time, and differences in abduction of the flexion angle of the hip and walking stride between the fixation side and the unaffected side in patients. Outcome scores were assessed at the last follow-up (minimum 5 years' follow-up).

\section{Results}

Of the 27 patients, 21 had unilateral anterior arthrodesis alone, and the average amount of blood loss among them was $130(33-271) \mathrm{ml}$. The average length of surgery was 190 (150-310) minutes. Four patients needed additional posterior fusion, and two patients required pelvic ring arthrodesis because fusion of the pubic symphysis was needed for uncontrolled severe pain over the pubic 

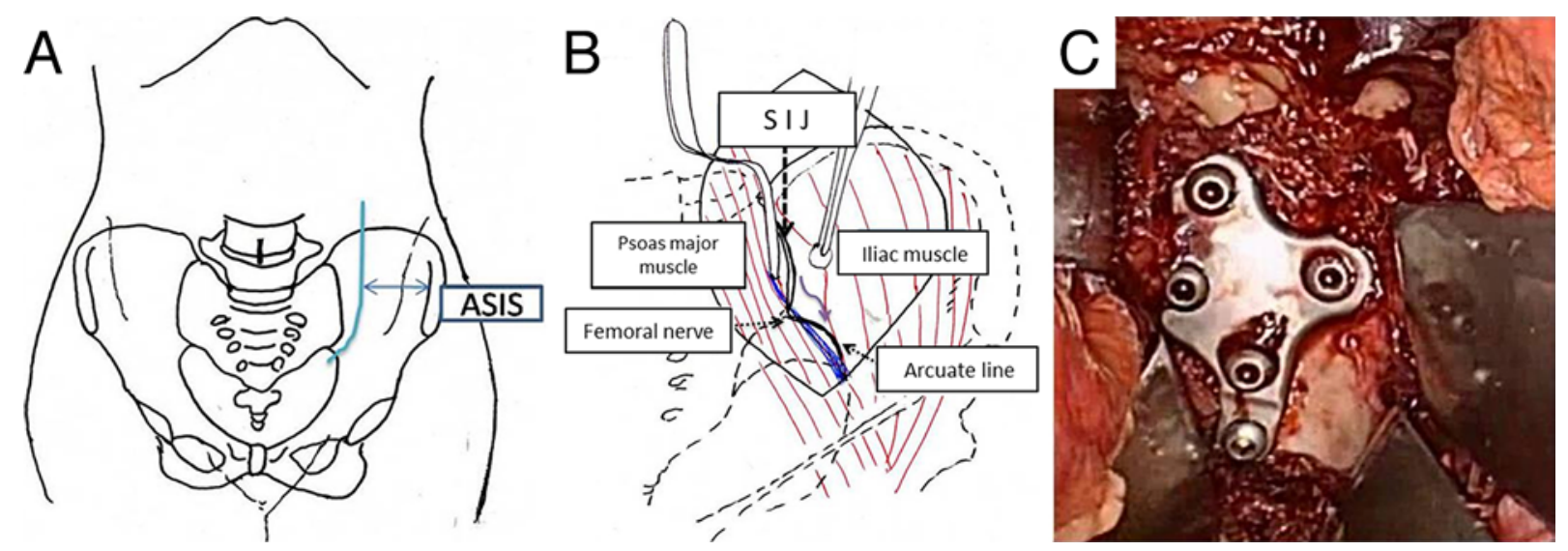

FIG. 4. Current anterior SIJ arthrodesis using the pararectal approach. A: A long longitudinal incision about $8-10 \mathrm{~cm}$ is made along the lateral border of the rectus abdominal muscle over the line of the SIJ, after identifying the SIJ by fluoroscopy in the same manner as in the former anterior approach. The external oblique muscle, internal oblique muscle, and transverse abdominal muscles are cut to reach the peritoneum. B: The psoas major and the iliac muscles are reached extraperitoneally by retracting the peritoneum medially. The anterior surface of the SIJ is exposed between the two muscles. C: The SIJ is curetted and fixed with a plate and screws in the same manner as in the former anterior approach. ASIS = anterior superior iliac spine. Figure is available in color online only.

symphysis, which developed after bilateral anterior SIJ arthrodesis.

\section{Bone Union}

Bone union of the joint was confirmed in all cases by CT examination (Fig. 6). Fusion of the SIJ was confirmed between 6 months and 1 year postoperatively in most cases. The area of bony union was classified into three groups based on the axial CT image showing the widest union area of the SIJ: 1) complete: bony union was confirmed in $\geq 80 \%$ of the SIJ area, 2) half: union in $\geq 50 \%$ and $<80 \%$ of the SIJ, and 3) partial: union in $<50 \%$ of the SIJ.

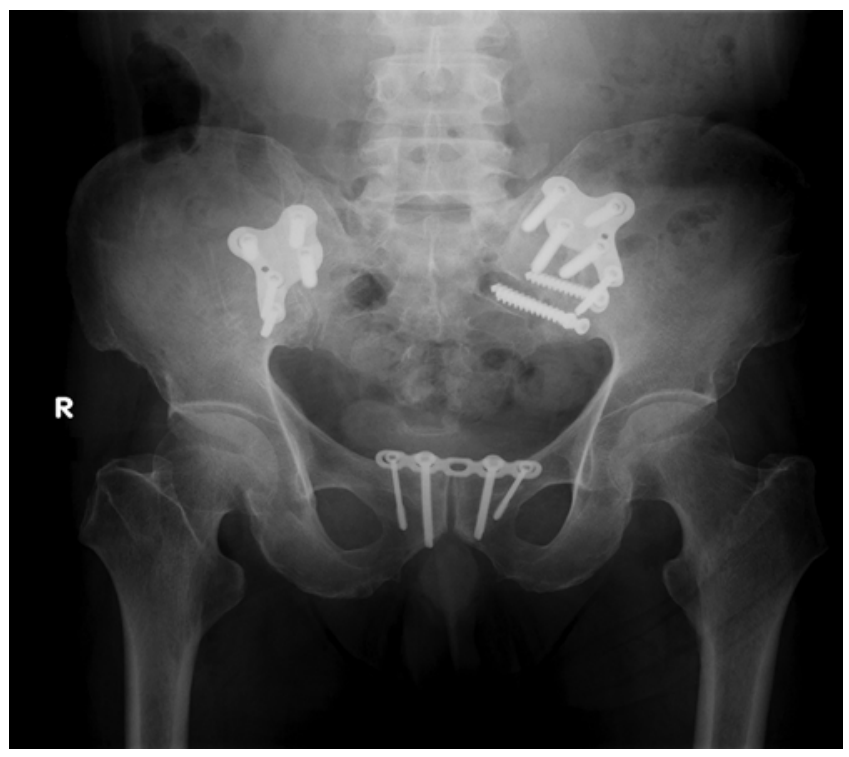

FIG. 5. Radiograph obtained after pelvic ring arthrodesis. We added fixation of the pubic symphysis using a plate and screws after bilateral anterior arthrodesis of the SIJ.
Twenty-one patients with unilateral anterior arthrodesis alone had bone union of the SIJ on CT: 12 in the complete union group, 7 in the half group, and 2 in the partial group. Among the 4 patients with additional posterior fusion, 3 were in the complete group and 1 was in the half group. Among the patients with pelvic ring arthrodesis, 1 was in the half group and 1 was in the partial group. In many cases, a wider fusion area yielded a better outcome; however, some patients had good results despite a small fusion area.

\section{Modified Macnab Criteria}

Among the 21 patients with unilateral anterior arthrodesis alone, 7 had an excellent outcome, 11 a good outcome, and 3 a fair outcome. Thus, $86 \%(18 / 21)$ of the patients indicated excellent or good results. Among the 4 patients with additional posterior fusion, 1 patient each had an excellent, a good, a fair, and a poor outcome. Of the 2 patients with pelvic ring arthrodesis, 1 had a good outcome and 1 a poor outcome (Table 1).

\section{Other Clinical Outcomes Among Patients With Unilateral Anterior Arthrodesis}

Regarding outcomes for those with unilateral anterior arthrodesis, the pain relief scale, VAS, and RDQ also showed significant improvement (Table 2). Compared with the preoperative condition, time sitting on a chair and walking time were significantly improved postoperatively in all patients (Fig. 7).

Among the 21 patients with unilateral anterior arthrodesis alone, most showed a reduction in the flexion-abduction angle of the hip and a loss in walking stride, compared to those of the unaffected side (Fig. 8).

\section{Complications}

Dislocation of a screw occurred in three patients. Lateral femoral cutaneous neuralgia developed in 7 of the 27 patients. Among these 7 patients, 6 had undergone the 

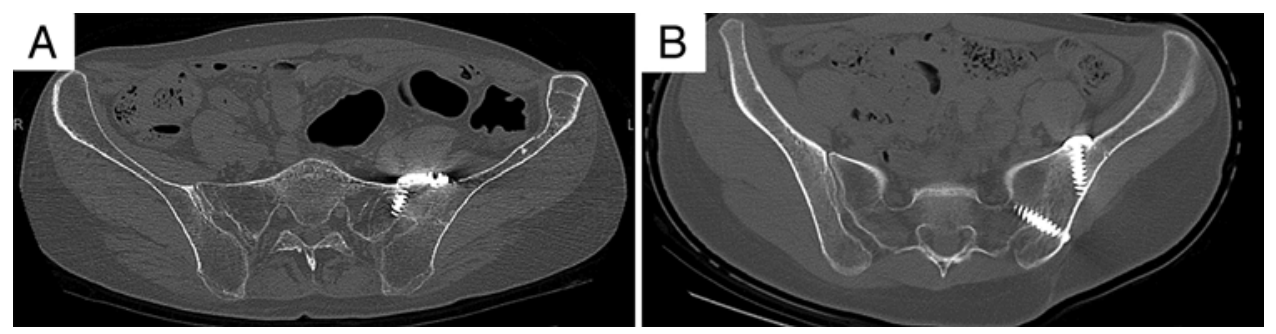

FIG. 6. Computed tomography images obtained in a patient who had undergone anterior arthrodesis (A) and in whom joint fusion was partially achieved, and in a patient who had undergone anterior and posterior arthrodesis (B) and in whom broad fusion of the joint was achieved by the fixation from anterior and posterior.

initial anterior method and 1 had undergone the current method. Hematoma formation was observed in 1 patient, but it disappeared naturally. After surgery, pain from the SIJ in the unaffected side occurred in 14 patients, most of whom were able to cope with SIJ injections except for 2 patients in whom pelvic ring fusion was performed. Lumbar radiculopathy was indicated in 5 cases prior to surgery. The symptoms in 3 patients worsened after the arthrodesis. Only 1 of these 3 patients needed decompression surgery for the affected lumbar nerve root due to ineffective nerve root block.

\section{Discussion}

When SIJ pain does not improve by conservative treatment and a patient's activities of daily living, such as walking or sitting, are severely restricted, SIJ arthrodesis should be considered. The posterior, lateral, or anterior approach has been used for SIJ arthrodesis; however, sufficient joint union has not been achieved..$^{2,8,13,20,27}$ Given that patients whose SIJ did not show complete bony union had not indicated good surgical results, bony fusion of the joint should be considered essential for pain relief. ${ }^{25}$ Anatomically, the approach to the SIJ via the posterior or the lateral approach is difficult to use to reach the joint surface and to curette the joint cavity sufficiently. Buchowski et al. ${ }^{4}$ and Waisbrod et al. ${ }^{27}$ reported 10\%-20\% nonunion after SIJ arthrodesis via the posterior approach. In addition, with the posterior approach it is inevitable to damage the posterior sacroiliac ligaments group, which is important for stability of the SIJ.

TABLE 1. Modified Macnab criteria

\begin{tabular}{ccccc}
\hline Rating & $\begin{array}{c}\text { No. } \\
\text { of } \\
\text { Cases }\end{array}$ & $\begin{array}{c}\text { Single } \\
\text { Anterior } \\
\text { Arthrodesis }\end{array}$ & $\begin{array}{c}\text { Additional } \\
\text { Posterior } \\
\text { Fusion }\end{array}$ & $\begin{array}{c}\text { Pelvic } \\
\text { Ring } \\
\text { Arthrodesis }\end{array}$ \\
\hline $\begin{array}{c}\text { Excellent: no restric- } \\
\text { tion in daily life }\end{array}$ & 8 & 7 & 1 & 0 \\
\hline $\begin{array}{c}\text { Good: occasional } \\
\text { pain; return to } \\
\text { modified work }\end{array}$ & 13 & 11 & 1 & 1 \\
\hline $\begin{array}{c}\text { Fair: some improve- } \\
\text { ment but unem- } \\
\text { ployed }\end{array}$ & 4 & 3 & 1 & 0 \\
\hline Poor: no improvement & 2 & 0 & 1 & 1 \\
\hline
\end{tabular}

Schütz et al. ${ }^{25}$ pointed out that it is important to restrain sinking of the sacrum when it receives an upper body load in order to have good results for SIJ arthrodesis. Radiographic analysis and investigation of the degenerative changes in the articular cartilage of the SIJ indicated that the stress of the standing load concentrates in the upper to middle part of the anterior portion of the SIJ. ${ }^{14,18}$ Anterior arthrodesis can prevent this sacral sinking because it allows one to curette this site, graft the bone, and fix the joint with a plate and screws under direct vision, leading to possible complete bony union of the SIJ. Bony union was achieved in all cases, although most were partial, and $78 \%$ of the patients had outcomes $\geq \operatorname{good}$ according to the modified Macnab criteria (Table 1).

In the present series, we had four cases in which posterior SIJ arthrodesis was added after the anterior surgery because the patient still complained of pain during daily activities. This indicated that there were cases in which the SIJ might not be controlled by anterior SIJ arthrodesis alone. Although bony fusion of the SIJ occurred in all cases, as confirmed by CT, it was partial, not whole, fusion of the joint. Even using the anterior approach, adequate curettage and bone graft of the joint over the entire surface is technically difficult since the shape of the SIJ is complicated - the anterior part of the joint is deep with a narrow and curved joint space. Partial bony union of the SIJ may permit minor distortion and movement of the joint, which can cause SIJ pain again in some cases.

In many patients with unilateral SIJ arthrodesis, hip flexion-abduction was restricted about $10^{\circ}-20^{\circ}$, and walking stride on the affected side was narrower than that on the nonoperated side. This suggests that anterior SIJ arthrodesis results in the restriction of hip flexion-abduction and stride. This restricted hip range of motion (ROM) may lead to difficulty sitting with the legs crossed when putting on or taking off socks. Since the hip joint was not di-

TABLE 2. Other clinical results for 21 patients with unilateral anterior arthrodesis alone

\begin{tabular}{lcccc}
\hline \multicolumn{1}{c}{ Scale } & $\begin{array}{c}\text { No. of } \\
\text { Patients }\end{array}$ & $\begin{array}{c}\text { Preop } \\
\text { (range) }\end{array}$ & $\begin{array}{c}\text { Postop } \\
\text { (range) }\end{array}$ & $\begin{array}{c}p \\
\text { Value }\end{array}$ \\
\hline Pain relief scale & 21 & 10 & $3.1(1-8)$ & \\
\hline VAS & 21 & $84.4(65-95)$ & $26.6(5-76)$ & $<0.001$ \\
\hline RDQ & 17 & $21.2(18-23)$ & $7.2(0-15)$ & $<0.001$ \\
\hline
\end{tabular}

A p value $<0.05$ indicates statistical significance. 

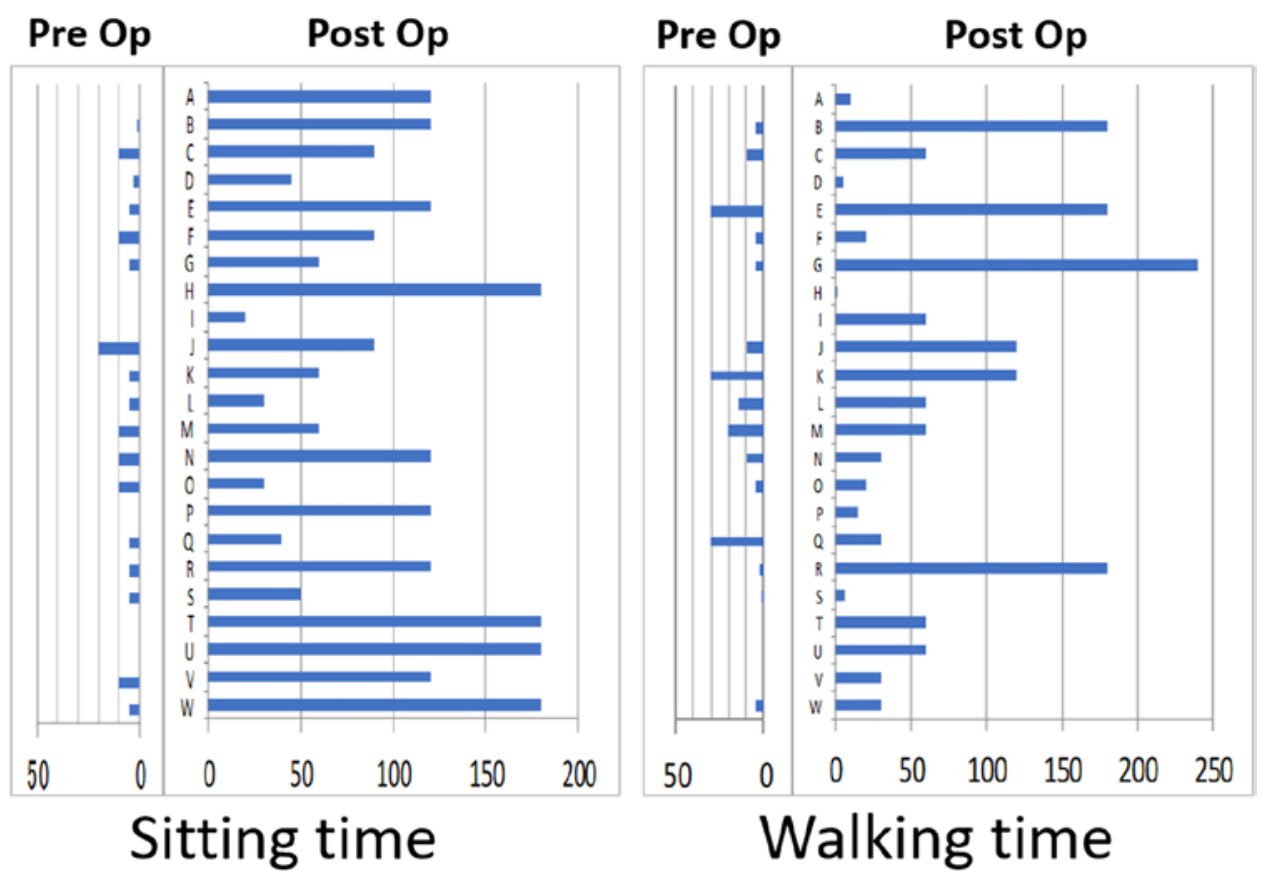

FIG. 7. Change in sitting time and walking time from preoperatively to postoperatively. Time sitting on a chair and time walking were improved significantly after the operation from an average of 6.7 minutes (range 0-20) to 111.4 minutes (range 30-180) and from 10.3 minutes (range $0-30$ ) to 81.7 minutes (range 1-240), respectively. Figure is available in color online only.

rectly managed during the SIJ arthrodesis, the restriction of hip ROM was not caused by an adhesion inside the hip joint. The operative invasion around the iliopsoas muscle
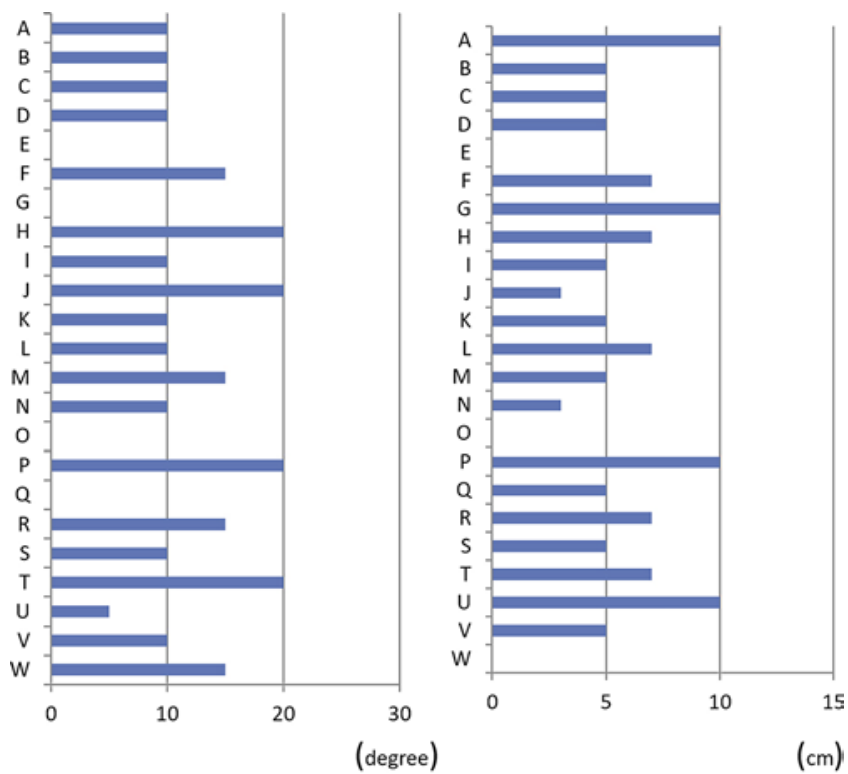

\section{Reduction of hip flexion-abduction}

\section{Reduction of walking} stride

FIG. 8. Reduction of hip flexion-abduction and walking stride on the affected side among the 21 patients with unilateral SIJ fixation. In comparison to the unaffected side, 19 showed a reduction in the flexion-abduction angle of the hip as much as an average of $11.8^{\circ}$ (range $5^{\circ}-20^{\circ}$ ), and most patients indicated an average $6.1-\mathrm{cm}$ (range 3-10 cm) loss of walking stride. Figure is available in color online only. may cause muscle degeneration and an adhesion of this muscle to the surrounding soft tissues. However, the iliopsoas muscle degeneration or adhesion with surrounding tissues may not cause the restriction of hip ROM because the iliopsoas muscle attaches to the lesser trochanter and is relaxed when the hip joint is flexed and abducted. Therefore, the hip ROM may be compounded by the hip joint itself and the SIJ.

In addition to the relatively small number of patients, there are several limitations to this study that should be mentioned. First, because of the process of trial and error of our SIJ surgeries, not all patients were treated using the same procedure. Second, we could not statistically compare the surgical results of unilateral anterior arthrodesis with those of added posterior arthrodesis or pelvic ring arthrodesis. Third, we did not evaluate the flexion-abduction angle of the hip and walking stride preoperatively. Despite these limitations, this is the first study indicating the long-term results of SIJ arthrodesis, which shows relatively good clinical results with confirmed bony union in all cases. Anterior arthrodesis should be useful in patients with severe chronic SIJ pain that has resisted conservative therapies.

It is undeniable that our anterior arthrodesis is a more morbid procedure than the novel minimally invasive methods. ${ }^{5,22}$ Despite this limitation, however, this arthrodesis has the advantage of curetting and fixing the main loadbearing area of the SIJ under direct vision, which results in definite bony union and stability. Furthermore, our anterior approach is an original and interesting procedure that reaches the SIJ without separating the iliac muscle from the iliac bone, and we believe that this approach is essential for managing infections in the SIJ and the pseudar- 
throsis that occurs after SIJ arthrodesis via the posterior or lateral approach. Thus, surgeons should know the technique of anterior SIJ arthrodesis.

\section{Conclusions}

Anterior SIJ arthrodesis was effective in most patients with severe SIJ pain resistant to conservative therapy because they had good bony union, pain relief for activities of daily living, and great improvement in sitting time and walking time, although the approach can be technically invasive and some patients will need additional posterior arthrodesis. The pararectal anterior approach would also be useful for patients with pelvic fractures near the SIJ.

\section{References}

1. Avila L Jr: Primary pyogenic infection of the sacro-iliac articulation. A new approach to the joint. Report of seven cases. J Bone Joint Surg Am 23-A:922-928, 1941

2. Belanger TA, Dall BE: Sacroiliac arthrodesis using a posterior midline fascial splitting approach and pedicle screw instrumentation: a new technique. J Spinal Disord 14:118-124, 2001

3. Bernard TN Jr, Cassidy JD: The sacroiliac joint syndrome: pathophysiology, diagnosis, and management, in Frymoyer JW (ed): The Adult Spine: Principles and Practice. New York: Raven Press, 1991, pp 2107-2130

4. Buchowski JM, Kebaish KM, Sinkov V, Cohen DB, Sieber AN, Kostuik JP: Functional and radiographic outcome of sacroiliac arthrodesis for the disorders of the sacroiliac joint. Spine J 5:520-529, 2005

5. Endres S, Ludwig E: Outcome of distraction interference arthrodesis of the sacroiliac joint for sacroiliac arthritis. Indian J Orthop 47:437-442, 2013

6. Fortin JD, Dwyer AP, West S, Pier J: Sacroiliac joint: pain referral maps upon applying a new injection/arthrography technique. Part I: Asymptomatic volunteers. Spine (Phila Pa 1976) 19:1475-1482, 1994

7. Gaenslen FJ: Sacro-iliac arthrodesis. Indications, author's technic and end-results. JAMA 89:2031-2035, 1927

8. Giannikas KA, Khan AM, Karski MT, Maxwell HA: Sacroiliac joint fusion for chronic pain: a simple technique avoiding the use of metalwork. Eur Spine J 13:253-256, 2004

9. Goldthwait JE, Osgood RB: A consideration of the pelvic articulations from an anatomical, pathological and clinical standpoint. Boston Med Surg J 152:593-601, 1905

10. Kurosawa D, Murakami E, Aizawa T: Referred pain location depends on the affected section of the sacroiliac joint. Eur Spine J 24:521-527, 2015

11. Lee JJ, Lee MK, Kim JE, Kim HZ, Park SH, Tae JH, et al: Pain relief scale is more highly correlated with numerical rating scale than with visual analogue scale in chronic pain patients. Pain Physician 18:E195-E200, 2015

12. Macnab I: Negative disc exploration. An analysis of the causes of nerve-root involvement in sixty-eight patients. $\mathbf{J}$ Bone Joint Surg Am 53:891-903, 1971

13. Mitchell JI: Surgical treatment of affections of the lumbosacral and sacroiliac joints. Surgery 4:33-43, 1938

14. Miura H: [Biomechanical properties of the sacroiliac joint.] Nippon Seikeigeka Gakkai Zasshi 61:1093-1105, 1987 (Jpn)

15. Mixter WJ, Barr JS: Rupture of the intervertebral disc with involvement of the spinal canal. N Engl J Med 211:210-215, 1934
16. Murakami E, Kanno H, Aizawa T, Okuno H, Noguchi K: [Sacroiliac joint arthrodesis for chronic sacroiliac joint pain.] J Lumbar Spine Disord 13:197-203, 2007 (Jpn)

17. Murakami E, Tanaka Y, Aizawa T, Ishizuka M, Kokubun S: Effect of periarticular and intraarticular lidocaine injections for sacroiliac joint pain: prospective comparative study. J Orthop Sci 12:274-280, 2007

18. Ohba S: [Morphological study of the sacroiliac joint of aged Japanese and macroscopic and microscopic observations on its articular surface.] Nippon Seikeigeka Gakkai Zasshi 59:675-689, 1985 (Jpn)

19. Patrick HT: Brachial neuritis and sciatica. JAMA 69:21762179, 1917

20. Pennal GF, Massiah KA: Nonunion and delayed union of fractures of the pelvis. Clin Orthop Relat Res (151):124129, 1980

21. Rand JA: Anterior sacro-iliac arthrodesis for post-traumatic sacro-iliac arthritis. A case report. J Bone Joint Surg Am 67:157-159, 1985

22. Rudolf L, Capobianco R: Five-year clinical and radiographic outcomes after minimally invasive sacroiliac joint fusion using triangular implants. Open Orthop J 8:375-383, 2014

23. Sakamoto N, Yamashita T, Takebayashi T, Sekine M, Ishii S: An electrophysiologic study of mechanoreceptors in the sacroiliac joint and adjacent tissues. Spine (Phila Pa 1976) 26:E468-E471, 2001

24. Schwarzer AC, Aprill CN, Bogduk N: The sacroiliac joint in chronic low back pain. Spine (Phila Pa 1976) 20:31-37, 1995

25. Schütz U, Grob D: Poor outcome following bilateral sacroiliac joint fusion for degenerative sacroiliac joint syndrome. Acta Orthop Belg 72:296-308, 2006

26. Smith-Petersen MN, Rogers WA: End-result study of arthrodesis of the sacro-iliac joint for arthritis-traumatic and non-traumatic. J Bone Joint Surg Am 8-A:118-136, 1926

27. Waisbrod H, Krainick JU, Gerbershagen HU: Sacroiliac joint arthrodesis for chronic lower back pain. Arch Orthop Trauma Surg 106:238-240, 1987

\section{Disclosures}

The authors report no conflict of interest concerning the materials or methods used in this study or the findings specified in this paper.

\section{Author Contributions}

Conception and design: Murakami, Aizawa. Acquisition of data: Murakami. Analysis and interpretation of data: Murakami, Kurosawa. Drafting the article: all authors. Critically revising the article: all authors. Reviewed submitted version of manuscript: all authors. Approved the final version of the manuscript on behalf of all authors: Murakami. Statistical analysis: Murakami. Administrative/technical/material support: Murakami, Aizawa. Study supervision: Murakami, Aizawa.

\section{Supplemental Information}

\section{Previous Presentations}

Portions of this work were presented in abstract form as proceedings at the Second International Conference on Sacroiliac Joint Surgery held on September 17, 2016, in Hamburg, Germany.

\section{Correspondence}

Eiichi Murakami: JCHO Sendai Hospital, Sendai, Japan. murakami@sendai-shaho.com. 